\title{
O uso do SIGAA: um estudo de caso sobre o processo de ensino-aprendizagem no componente curricular máquinas elétricas no curso técnico em eletroeletrônica
}

Paulo Wagner Lopes-Silva paulo.wagner@ifal.edu.br 0000-0001-9154-7156 Instituto Federal de Alagoas, Arapiraca, Alagoas, Brasil.

Ednaldo Farias Gomes ednaldo.farias@ifal.edu.br 0000-0001-6789-6460 Instituto Federal de Alagoas, Arapiraca, Alagoas, Brasil.

\author{
RESUMO
}

O presente estudo investiga o uso das potencialidades pedagógicas do SIGAA como parte integradora das ações educativas em cursos técnicos na modalidade presencial. Esta pesquisa foi desenvolvida usando a metodologia da pesquisa-ação e considerou a percepção dos sujeitos participantes e suas reflexões sobre o uso dos recursos do ambiente. Para a coleta de dados foram usados um questionário e recursos de Estatística do SIGAA, os registros e constatações dos pesquisadores e um questionário semiestruturado aplicado aos participantes. Os três instrumentos de coleta de dados fornecem dados quantitativos e qualitativos usados para afirmar e/ou infirmar as percepções acerca do ambiente. Os resultados mostram que os participantes percebem a contribuição do Sistema no processo ensino-aprendizagem e o inferem como subutilizado. Com algumas ressalvas sobre o acesso via dispositivos móveis e instabilidades pontuais, o SIGAA facilita e amplia o acesso aos materiais e conteúdos didáticos trabalhados, contribui com a interação entre professor $e$ aluno e auxilia nas ações avaliativas, destacando-se como provável aliado no cotidiano do ensino presencial.
\end{abstract}

PALAVRAS-CHAVE: Ambiente virtual de ensino-aprendizagem. Ensino presencial. SIGAA. Turma virtual. Pesquisa-ação. 


\section{INTRODUÇÃO}

O Brasil figura dentre os países com os piores índices na educação (OECD/PISA, 2018). Esse é um problema complexo e as formas de melhorar esses índices são igualmente complexas e passam por diversas esferas de poder. As possíveis soluções não encontram convergência nem entre os pesquisadores em educação tampouco entre os políticos. Nesse lugar de divergências, poucas iniciativas encontram consenso de parcela substancial dos envolvidos (políticos, educadores e pesquisadores). Entende-se, pois, que a melhoria desses índices depende de diversas variantes em níveis distintos de responsabilidade e ação.

Uma dessas ações que encontra consenso de parte dos envolvidos é o uso das Tecnologias de Informação e Comunicação (TICs) acompanhado de metodologias compatíveis. Há diversos tipos de TICs destinadas a educação, desde aplicativo para resolver pequenos problemas matemático de baixa complexidade ou dicionários até sistemas robustos de Ambientes Virtuais de Ensino-Aprendizagem (AVEA), sendo este entendido como um sistema computacional destinado a veicular conteúdos e permitir a interação entre os atores do processo educativo (PEREIRA et al., 2007, p. 4). Além disso, pode suportar ferramentas de administração dos vários aspectos da ação educativa, como frequência, registro de conteúdo, avaliação entre outros.

O desenvolvimento desses ambientes foi e é impulsionado, majoritariamente, para serem usados em Educação a Distância (EAD), porém seus recursos podem e devem ser utilizados para potencializar a educação presencial (TORI, 2009, p. 121). Nos cursos presenciais, além das atividades e experiências notadamente em sala de aula, são previstas também atividades para os alunos noutros espaços, ou a distância, desse modo o uso de AVEA na educação presencial pode conferir um potencial expressivo de comunicação que diminuiria as barreiras de espaço e tempo, colaborando com a execução dessas atividades. (TORI, 2009, p.122).

Santos, Toczek e Gimenes (2014, p. 110) apresentam alguns argumentos a favor da utilização de ambientes virtuais no ensino presencial. Para eles, o AVEA representa uma alternativa para dinamizar as aulas e tornar o ensino mais agradável e interessante para o aluno, além de inserir a tecnologia diretamente no contexto escolar.

Com o uso de AVEA o aluno poderá ter à sua disposição o ambiente virtual com materiais e conteúdos organizados de forma a simplificar sua busca. Além disso, também poderá encaminhar dúvidas pelo ambiente e compartilhá-las com outros participantes, gerando dessa forma, integração e construção ativa de conhecimento. Esses autores explicam que o AVEA oferece possibilidade de organização para o ensino presencial pelo uso das ferramentas, tais como fórum, chats, arquivos para download, tarefas, entre outras.

Segundo Costa; e Mendonça (2014), Guérios e Sausen (2012), Oliveira e Cortimiglia (2015) e Santos, Toczek e Gimenes (2014) um dos principais ambientes virtuais utilizado no Brasil é o Modular Object-Oriented Dynamic Learning Environment (Moodle), largamente usado na educação a distância, semipresencial e em algumas iniciativas em cursos presenciais

Outro tipo de sistema computacional amplamente utilizado em EAD e presencial é Sistema de Gerenciamento Acadêmico ou Sistema Acadêmico, que possui a função de gerenciar as mais diversas áreas de um ambiente acadêmico. 
Um sistema acadêmico de referência no Brasil é o Sistema Integrado de Gestão (SIG), desenvolvido pela Universidade Federal do Rio Grande do Norte (UFRN). O SIG foi criado com o objetivo de funcionar integrado a todos os sistemas que uma universidade necessitasse, como o sistema de gestão de biblioteca, sistema de recursos humanos, entre outros.

O SIG é composto de vários sistemas: Sistema Integrado de Gestão de Patrimônio, Administração e Contratos (SIPAC), Sistema Integrado de Gestão de Recursos Humanos (SIGRH), Sistema Integrado de Gestão de Planejamento e de Projetos (SIGPP), Sistema Integrado de Gestão de Atividades Acadêmicas (SIGAA) dentre outros (SINFO, 2017a, p. 1). Cada um desses sistemas possui outras partes acopladas chamadas de módulos, responsáveis por tarefas bem definidas, essas partes são chamadas de módulos, como o SIGAA. Dentre esses módulos destacase a Turma Virtual que guarda compatibilidades com os recursos e funcionalidades que comumente se encontram em um AVEA como o Moodle. (NETO; LIMA, 2009, p. 1).

A Turma Virtual do SIGAA, assim como noutros AVEA, possui um potencial enorme de uso em educação presencial, desde que esteja configurado para este fim. Ele pode ampliar a sala de aula, facilitar e organizar os estudos dos sujeitos envolvidos, ampliar a integração, dinamizar as aulas, facilitar a avaliação e outras possibilidades, fazendo necessárias, para tal, uma metodologia adequada e capacitação docente.

Os módulos do SIG foram adotados pelo Instituto Federal de Alagoas (IFAL) e por outras instituições da Rede Federal em 2014 e 2015. Quando o SIGAA e os demais módulos do SIG começaram a ser utilizados, as recomendações eram lançar frequência, notas e os conteúdos da aula. Todavia, enquanto usuário verificou-se que a possibilidade de uso como ambiente virtual são visíveis e se mostram com diversas vantagens como apontado por Carvalho, (2018), Delgado e Haguenauer (2010), Neto e Lima (2009), Rodrigues et al. (2011), Santos, Toczek, Gimenes (2014) e Yunoki (2009).

Diante das possibilidades do Sistema surgiu uma inquietação em relação a subutilização do módulo do Turma Virtual integrante do SIGAA Diante desse panorama, o objetivo desse artigo é investigar o uso das potencialidades pedagógicas do SIGAA, módulo Turma Virtual, como parte integradora das ações educativas presenciais e a distância do ensino-aprendizagem, tomado como espaço de pesquisa a disciplina de máquinas elétricas em um curso técnico na modalidade presencial.

\section{EDUCAÇÃO A DISTÂNCIA}

A EAD, entendida como a modalidade na qual os sujeitos se encontram em tempos/espaços distintos e possuem os processos de interação e interatividade mediados por artefatos de tecnologia, ao contrário do que se possa inferir, não é uma modalidade de ensino recente. Essa modalidade de ensino surgiu em março de 1728 com um anúncio no jornal de circulação regional, Gazette de Boston (EUA). Nele, Caleb Philips ofertava aulas por correspondência (NUNES, 2009, p. 23) para alunos interessados em todo território dos Estados Unidos. 
Já no Brasil, os primeiros registros de cursos ofertados por correspondência remontam de pouco antes de 1900, também se deu por anúncios em jornais em circulação na cidade Rio de Janeiro e eram ofertados por professores particulares. Já os primeiros estabelecimentos de ensino a distância a atuar no Brasil foram as Escolas Internacionais em 1904, (ALVES, 2009, p. 9).

A EAD ao longo dos anos avançou principalmente nas tecnologias empregadas, sendo este avanço a principal inovação na educação das últimas décadas (NUNES, 2009, p. 2). As novas tecnologias propiciaram o surgimento de Ambientes Virtuais de Ensino e Aprendizagem (AVEA). Esses sistemas virtuais rapidamente se espalharam e se tornaram um dos principais meios de comunicação dessa modalidade de educação.

O surgimento dessas plataformas modificou não apenas a forma de oferta de cursos a distância, mas vêm contribuindo com a educação presencial. Esse efeito de integração entre a educação presencial e a distância já vem acontecendo há quase trinta anos segundo Nunes (2009, p. 2).

Para Tori (2009, p. 121) "O desafio de se envolver, acompanhar e interagir com alunos a distância gerou soluções eficazes para EAD que podem - e devem enriquecer cursos que já contam com a vantagem da presença física do aluno". Este autor acredita que seja difícil conceber um curso presencial que não possua atividades a distância e, nesse cenário, a aplicação de conquistas tecnológicas e metodológicas da área de EAD em cursos presenciais possui grande potencial para melhorar a qualidade e a eficiência da aprendizagem.

\section{SISTEMA INTEGRADO DE GESTÃO DE ATIVIDADES ACADÊMICAS - SIGAA}

O desenvolvimento tecnológico é uma ocorrência contínua que ocupa as mais diversas esferas da vida humana, e, no que diz respeito à educação ocupa espaços, formais e informais, coletivos e individuais de aprendizagem. Um dos equipamentos importantes nestes avanços é o computador, que pode ser compreendido, inicialmente, como uma calculadora; composta de uma parte física, ou hardware, que são as peças e da parte lógica, ou software; compreendido como um conjunto de instruções que instrui o hardware sobre a maneira que ele deve executar uma tarefa específica (DICWEB, 2019).

As tecnologias continuaram a avançar, tanto em termos de hardwares quanto de softwares. Estes avanços possibilitaram a criação de programas mais complexos e a interligação de diversos softwares, a fim de desempenharem funções mais abrangentes dando origem aos sistemas.

Um sistema pode ser definido como um conjunto de programas ou grupos de programas (softwares) ou um grupo de elementos inter-relacionados que trabalham de forma organizada para desempenharem funções específicas.

Todo sistema atua ou desempenha funções em uma determinada área. Um sistema de gerenciamento, por exemplo, tem por função organizar as tarefas inerentes ao serviço prestado. Nesses sistemas, normalmente, existe um conjunto de softwares com funções relativas a uma atividade específica como organizar o estoque, gerenciar o fluxo de caixa, entre outras.

Atuando de forma independente, cada programa não realizaria sua função de forma satisfatória. Sem as informações dos produtos que são vendidos o software 
de gerenciamento de estoque não listaria os produtos que precisam ser comprados. Assim, como medida de eficiência, os programas que compõem um sistema desempenham suas funções de forma inter-relacionadas.

Eles conseguem gerenciar atividades complexas e, dessa forma, facilitar e agilizar tarefas em diversas áreas, como a educação. Nesse caso, ela é uma das áreas que se beneficia com o uso de sistemas como os AVEA e os sistemas de gerenciamento acadêmico. O primeiro deles, é um sistema que tem por função estabelecer a comunicação entre professores e alunos, bem como dinamizar a partir de recursos e ferramentas como vídeo aulas, exercícios, chats e fóruns (SILVA; FIGUEIREDO, 2012, p. 3).

O SIGAA começou a ser produzido pela Superintendência de Informática (SINFO) da UFRN em agosto de 2007 (NETO; LIMA, 2009, p. 1) e pode ser definido como um conjunto de sistemas voltado para a execução de atividades acadêmicas e administrativas (GERBASI; SILVA, 2017, p. 170) ou um sistema de informação web corporativo que informatiza os procedimentos da área acadêmica compartimentados em módulos distintos (BARROCA FILHO; AQUINO; SANTA ROSA, 2013, p. 93).

No início, esse Sistema Acadêmico não possuía um AVEA e já havia a necessidade de fazer uso dos seus recursos no ensino presencial. Percebendo-se a necessidade "decidiu-se em 2008 desenvolver uma ferramenta nova de apoio ao ensino presencial incorporada ao SIGAA" (NETO; LIMA, 2009, p. 2) denominada Turma Virtual. Esse módulo deveria ser intuitivo e de fácil acesso, facilitando a comunicação entre os sujeitos, permitindo ao professor, inclusive, o uso de materiais postados em turmas anteriores (NETO; LIMA, 2009, p. 2).

O SIGAA informatiza os procedimentos da área acadêmica a partir de diversos módulos como os de graduação, pós-graduação, ensino técnico, ensino médio e infantil, submissão e controle de projetos e bolsistas de pesquisa, submissão e controle de ações de extensão, submissão e controle dos projetos de ensino (monitoria e inovações), registro e relatórios da produção acadêmica dos docentes, atividades de ensino a distância e um ambiente virtual (SINFO, 2017b).

Nesse sentido, o IFAL utiliza o SIG para gerenciar as mais diversas atividades desenvolvidas em suas instalações. Essa pesquisa, por se localizar nessa instituição, fez uso do Ambiente Virtual de Ensino-Aprendizagem do SIGAA, denominado de Turma Virtual, como objeto de investigação para realizar suas ações de intervenção. O SIGAA é utilizado para registro acadêmico, porém a Turma Virtual apresenta várias funções que podem expandir as perspectivas e atividades desenvolvidas em sala de aula para além desse espaço e do tempo a ele destinados.

Neste estudo, a intervenção, do tipo pesquisa-ação, será efetuada no componente curricular de Máquinas Elétricas do Curso Técnico Integrado de Nível Médio em Eletroeletrônica que se dispõe como um componente de ordem prática na matriz curricular deste curso. Para isso, utiliza-se um laboratório de máquinas elétricas com kits didáticos das máquinas estudadas: transformadores, motores e geradores. Nesse espaço de atuação dos pesquisadores, as principais ferramentas de avaliação são montagem de experimentos, elaboração de relatório, observações sobre experiências, questionários e avaliações teóricas. 


\section{METODOLOGIA}

Uma das motivações para realização desta pesquisa foi a possibilidade de usar as ferramentas do SIGAA como facilitadoras dos processos de ensinoaprendizagem e avaliação; buscando facilitar e ampliar o acesso aos materiais e conteúdos didáticos trabalhados, ampliar a interação entre professor e aluno e auxiliar nas ações avaliativas. Desse modo, a questão que motivou a pesquisa pode ser sintetizada: É possível afirmar que o uso dos recursos do AVEA Turma Virtual sejam facilitadores dos processos de ensino-aprendizagem em cursos presenciais?

No intuito de estabelecer um exercício de auto-observação e de observação de outros sujeitos, a intervenção pautada na pesquisa-ação se justifica por fornecer os insumos necessários para responder à questão anterior à medida que localiza os sujeitos imersos no objeto de análise, sem excluir o rigor científico. Dessa forma, planejar e executar alterações na prática cotidiana da sala de aula, inserindo o uso dos recursos do AVEA escolhidos e realizando as devidas observações e análises acerca das alterações ocorridas, compõe o conjunto de ações adotadas. Alguns autores, como Thiollent (2011, p. 81) e Tripp (2005, p. 446) defendem que uma investigação que oscile entre uma ação no campo da prática e uma investigação a respeito dela descreve o ciclo de uma pesquisa-ação.

São diversas as possíveis definições de pesquisa-ação. Para Tripp (2005, p. 443) a pesquisa-ação é um tipo de investigação-ação e é definida como "toda tentativa continuada, sistemática e empiricamente fundamentada de aprimorar a prática". Já para Thiollent (2011):

\footnotetext{
[...] a pesquisa-ação é um tipo de pesquisa social com base empírica que é concebida e realizada em estreita associação com uma ação ou com a resolução de um problema coletivo e no qual os pesquisadores e os participantes representativos da situação ou do problema estão envolvidos de modo cooperativo ou participativo (THIOLLENT, 2011, p. 20).
}

A pesquisa-ação de cunho educacional é uma estratégia para o desenvolvimento de professores e pesquisadores de modo que eles possam utilizar suas pesquisas para aprimorar as relações de ensino e aprendizagem (TRIPP, 2005, p. 445). Como já mencionado, tanto para Thiollent (2011, p. 81) quanto para Tripp $(2005$, p. 446) o ciclo básico da pesquisa-ação passa por uma oscilação entre uma ação no campo da prática e uma investigação a respeito dela. Tripp (2005, p. 446) ainda apresenta uma constatação mais ampla do ciclo da investigação-ação com quatro fases: planejar, agir, descrever e avaliar.

Essas fases foram utilizadas nessa investigação e, a partir do problema de pesquisa foram planejadas ações que resultaram em uma implementação de recursos da Turma Virtual do SIGAA. Tal execução visou melhorar as práticas de ensinar e aprender. Durante o uso quotidiano dos recursos do AVEA foi monitorado e descrito os efeitos e avaliado os resultados do uso de tais ferramentas.

Adotou-se o SIGAA como ambiente para a integração das ações de ensino de Máquinas Elétricas do 4ㅇa ano do Curso Técnico Integrado em Eletroeletrônica do IFAL Campus Arapiraca e contou com 17 sujeitos participantes da pesquisa, durante 2 meses e meio (outubro - dezembro/ 2018). 
Os instrumentos de coleta de dados foram escolhidos devido ao formato e metodologia da pesquisa. Foram três (3) os instrumentos utilizados. O primeiro é o recurso de Estatística da própria Turma Virtual, nele é possível visualizar diversos dados quantitativos sobre a turma. O menu Estatística possui 6 opções: Estatística, Situação dos Discentes, Estatística de Notas, Relatório de Acesso, Relatório de Ações e Gráfico de Acesso.

Cada seleção desse menu apresenta diferentes opções, a Estatística durante o período da pesquisa apresentou uma mensagem de erro. Já a Situação dos Discentes, "Permite gerar gráficos da situação dos discentes" (SINFO, 2018, p. 3); o resultado dessa opção é um gráfico que mostra a porcentagem de aprovados, reprovados por nota e por falta, que trancaram matrícula, entre outras informações. Para ampliar a análise a operação Estatística de Notas permite visualizar um gráfico de notas dos discentes.

O Relatório de Acesso apresenta um panorama geral da frequência com que acessou a Turma Virtual e detalha o que fez, como quantos e quais arquivos lidou, quais conteúdos acessou e a data e hora desse acesso. Para gerar informações mais detalhadas sobre os dados acessados existe o Relatório de Ações, que permite filtrar por ações e em quais recursos, por usuário e em qual período. Na última opção, Gráfico de Acesso, é possível visualizar um gráfico de ingressos à turma virtual.

Os outros dois instrumentos de coleta de dados foram os registros e constatações dos pesquisadores e o questionário semiestruturado aplicado aos participantes ao final da intervenção. O Quadro 1 apresenta as características, aqui denominadas pela autora como pontos fortes e fracos do questionário e da observação direta.

Quadro 1 - Comparação entre questionário e observação direta

\begin{tabular}{|c|c|c|}
\hline Técnica de coleta & Pontos Fortes & Pontos Fracos \\
\hline Questionário & $\begin{array}{l}\text { - Garante anonimato; } \\
\text { - Questões objetivas; } \\
\text { - Questões padronizadas } \\
\text { garantem uniformidade; } \\
\text { - Flexibilidade no tempo } \\
\text { de resposta; } \\
\text { - Facilidade de conversão } \\
\text { dos dados; } \\
\text { - Custo razoável. }\end{array}$ & $\begin{array}{l}\text { - Inviabilidade de comprovar respostas } \\
\text { ou esclarecê-las; } \\
\text { - Dificuldade em pontuar questões } \\
\text { abertas; } \\
\text { - Possibilita respostas influenciadas } \\
\text { pelo “desejo de nivelamento social”; } \\
\text { - Restrito a pessoas aptas à leitura; } \\
\text { - Pode ter itens ambíguos. }\end{array}$ \\
\hline Observação direta & $\begin{array}{l}\text { - Capacidade de captar o } \\
\text { comportamento natural; } \\
\text { - Redução da influência } \\
\text { do "desejo de } \\
\text { nivelamento social"; } \\
\text { - Nível de intromissão } \\
\text { relativamente baixo; } \\
\text { - Confiabilidade. }\end{array}$ & $\begin{array}{c}\text { - Polarizada pelo observador; } \\
\text { - Necessidade de treinamento } \\
\text { especializado; } \\
\text { - Efeitos do observador nas pessoas; } \\
\text { - Pouco confiável para observações } \\
\text { com inferências complexas; } \\
\text { - Não garante anonimato; } \\
\text { - Observação de interpretação } \\
\text { complexas; } \\
\text { - Não esclarece o observado; } \\
\text { - Número restrito de variáveis. }\end{array}$ \\
\hline
\end{tabular}

Fonte: Ribeiro (2008). 
Os três instrumentos de coleta foram usados em conjunto a fim de garantir legitimidade e verificação aos dados coletados e minimizar as fragilidades que cada instrumento teria individualmente. A análise dos dados fornecidos pelo SIGAA (Estatística) foi utilizada como fonte de confirmação ou refutação dos dados coletados pelos demais instrumentos.

O gerenciamento do ambiente foi realizado e supervisionado pelo docente da referida unidade curricular, responsável pela manutenção dos conteúdos disponibilizados na Turma Virtual. Além disso, na condição de tutor, responsabilizou-se pela mediação de diálogos e discussões inerentes aos temas abordados. Também foi de sua responsabilidade a elaboração dos materiais e atividades de apoio ao processo de ensino-aprendizagem. Esses materiais foram concebidos em observância à individualidade dos sujeitos, procurando integrá-los às ações desenvolvidas e estabelecendo o desafio de executar uma relação dialógica por meio do acompanhamento.

Dessa feita, o material didático em questão fazia previsão de aulas teóricas em sala de aula convencional e aulas práticas em laboratório específico. No SIGAA foram disponibilizados os materiais utilizados nas aulas presenciais e roteiros para as aulas práticas. Além do compartilhamento de arquivos, foram utilizados os seguintes recursos: notícias, fóruns, enquetes, tarefas (offline, texto online e envio de arquivo) e questionários.

Ao final da pesquisa os participantes foram convidados a responder, de maneira voluntária, o questionário semiestruturado sobre o uso da ferramenta SIGAA com a finalidade de avaliar em que medida o uso do ambiente interferiu na apropriação de conhecimento. Para efeito de comparação, foram analisados conjuntamente com as respostas do questionário a participação dos alunos no AVEA utilizado.

\section{INTERVENÇÃO}

O componente curricular Máquinas Elétricas possui carga horária de $120 \mathrm{~h}$ aulas e aproximadamente $40 \%$ dessa carga horária é em laboratório realizando experimentos. Essa carga horária se justifica pois, pela execução de experimentos os discentes têm a oportunidade de verificar e experimentar os componentes internos dessas máquinas, como se relacionam e qual a função de cada componente no funcionamento geral.

Para realizar as práticas, usou-se o laboratório OpenLab da DeLorenzo (Figura 1). Nele, monta-se as máquinas objeto de estudo, fazem-na funcionar e variam a carga aplicada ao equipamento, simulando uma situação real de funcionamento. Estas atividades práticas promovem a possibilidade de ampliar a compreensão do discente acerca da máquina estudada. 


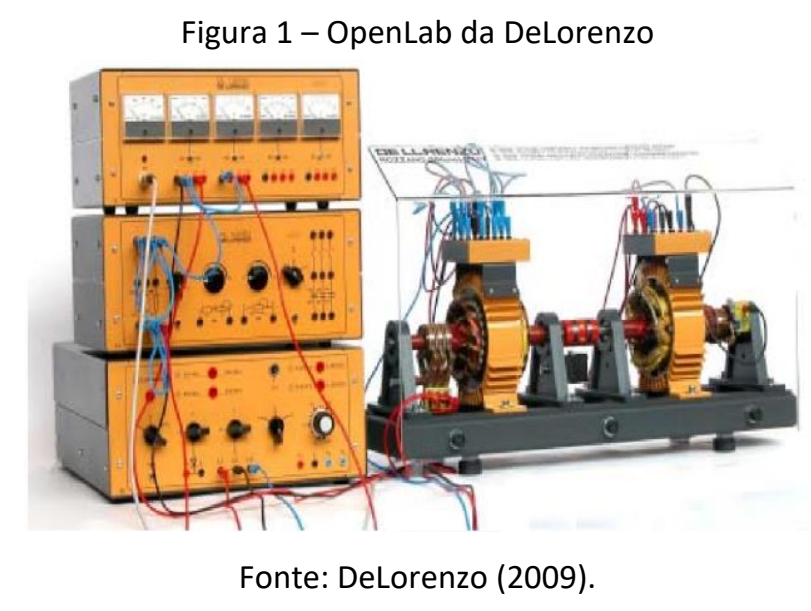

$\mathrm{Na}$ ocasião, a turma contava com 21 alunos matriculados, dos quais 4 decidiram não participar, sendo a pesquisa desenvolvida com 17 participantes. Em relação à faixa etária, o grupo pode ser considerado homogêneo, com idades entre 17 e 19 anos. Após ser lido e discutido com os participantes, o termo de consentimento livre e esclarecido foi entregue a todos e, para os casos de sujeitos menores de 18 anos, o termo foi assinado pelo responsável legal.

A avaliação do ensino-aprendizagem foi centrada no discente e usou como ferramenta principal os experimentos desenvolvidos. A turma foi dividida em 6 grupos, sendo 3 com 3 integrantes cada e 3 grupos com 4 integrantes, cada grupo realizou duas experiências. Cada equipe recebeu um roteiro compartilhado previamente, que continha os objetivos, procedimentos e um guia de quais valores devem ser registrados e como devem analisar os dados coletados na prática. Esse material também serviu de guia na formulação das conclusões do relatório que, nessa vivência configurou-se como tarefa de envio de arquivo no SIGAA. O guia solicitou que a equipe elabore gráficos que auxiliem outros discentes na percepção de como as diversas grandezas se inter-relacionam.

As equipes apresentaram um breve resumo do roteiro, que guiou na execução da experiência, com a finalidade de estudar a experiência e simplificar os passos. Após realizarem a montagem do experimento, a equipe explicou para os demais discentes a teoria que fundamenta sua experiência, o funcionamento da máquina que serve de base para sua prática e demostrou seu funcionamento aos demais.

Após a explicação da equipe responsável pelo experimento, os ouvintes foram provocados a escrever um resumo do que entenderam sobre o princípio de funcionamento e as características da máquina. Os resumos foram entregues e serviram de base para a avaliação do grupo (que realizou a experiência) e, também, da plateia que elaboraram os resumos. A forma de avaliação das equipes pela realização da experiência se deu pelos resumos e pelos itens: pontualidade, qualidade do resumo do roteiro, apresentação da teoria e da experiência e execução do experimento. Além disso, como registro, cada grupo ainda enviava um relatório por meio de uma tarefa de envio de arquivo no SIGAA (Figura 2). 
Figura 2 - Vista do aluno da tarefa de envio de arquivo

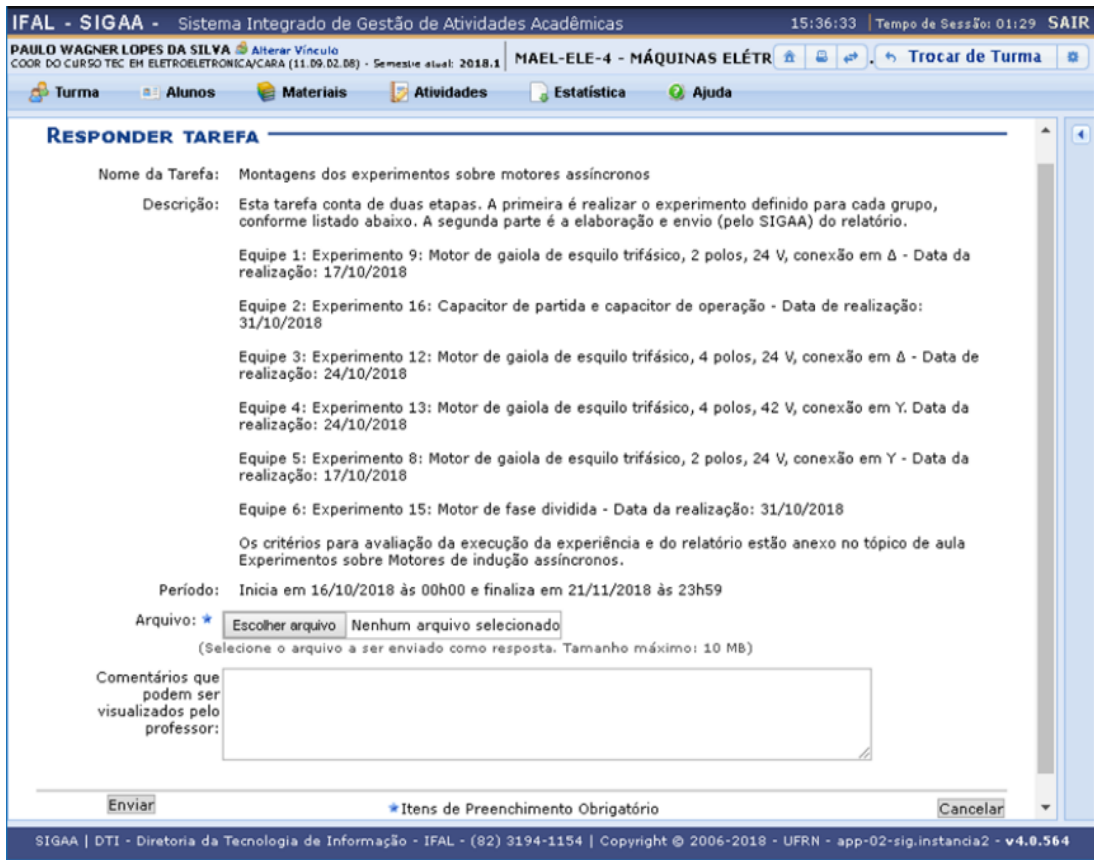

Fonte: Autores (2018).

Os discentes foram convidados a avaliarem as experiências práticas utilizando como proposta uma tarefa de texto online pelo SIGAA; a visualização nesta tarefa, é mostrada no espaço descrito na Figura 3.

Figura 3 - Visão do aluno da tarefa de avaliação dos experimentos

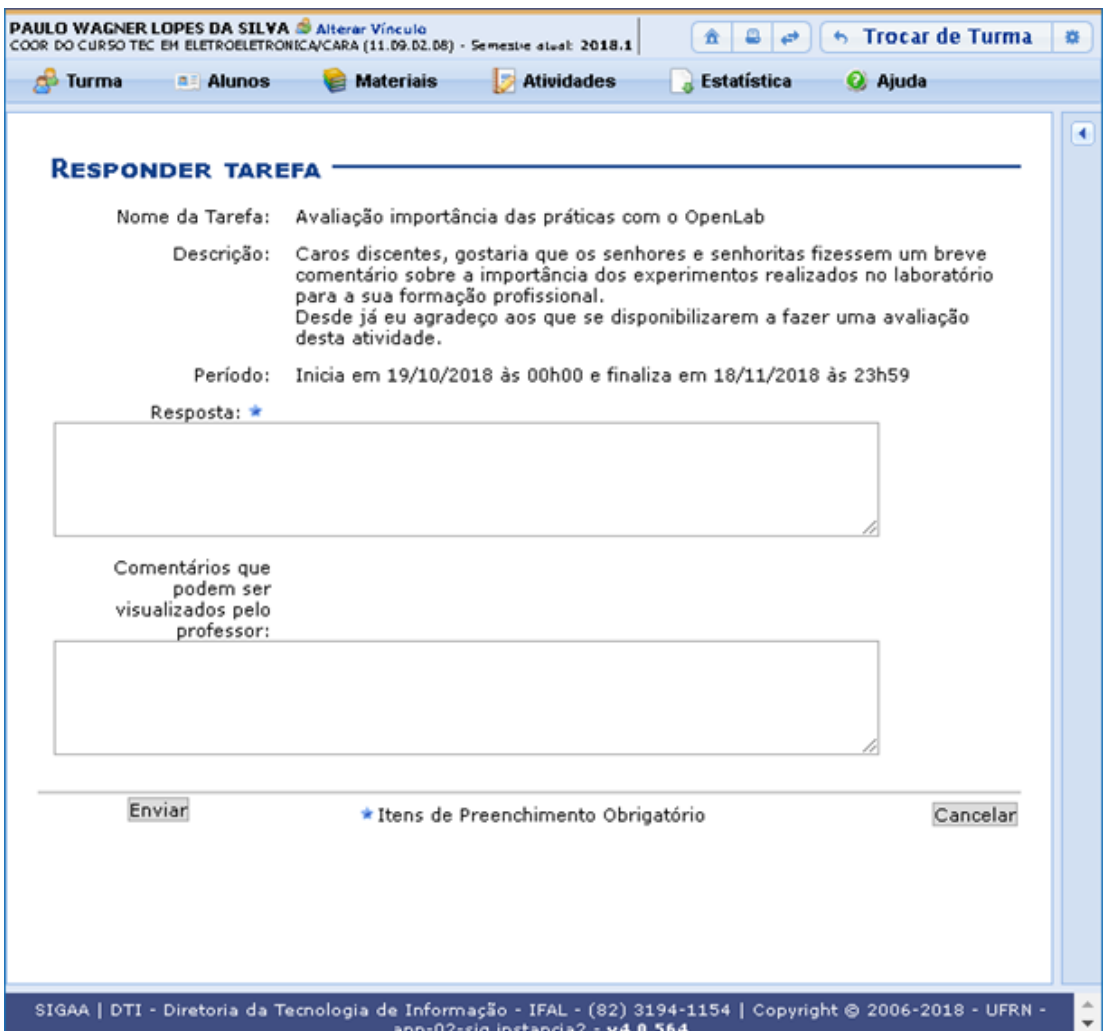


Durante toda a realização dos experimentos, os participantes puderam compartilhar dicas, materiais, vídeos e informações sobre os experimentos, além de se comunicarem com outros sujeitos por meio de um fórum, mediado pelo docente (Figura 4). O fórum foi dividido em 6 tópicos, um para cada experiência, neles todo tipo de informação que achassem relevantes sobre sua vivência em Máquinas Elétricas puderam ser registradas.

Figura 4 - Fórum sobre os experimentos

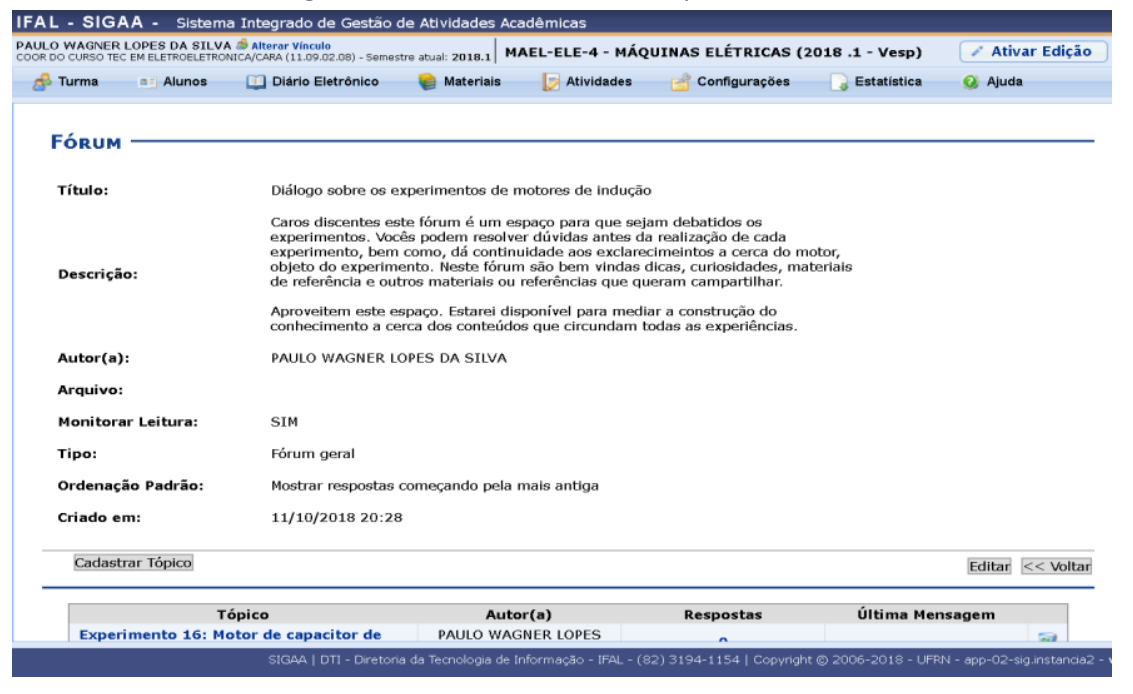

Fonte: Autores (2018).

A percepção dos discentes é essencial para investigar as potencialidades pedagógicas de qualquer AVEA, visto que eles são usuários do ambiente. Partindo desse princípio, os resultados e as observações e o questionário foram destinados a registrar as impressões dos participantes de pesquisa sobre o ambiente e suas ferramentas.

Reforça-se, todavia, que os resultados e análises são advindos da análise dos dados estatísticos fornecidos pelo ambiente e apresentados e discutidos posteriormente e que seu caráter conclusivo conduz a estabelecer leituras possíveis para as contribuições do uso do AVEA nas relações de ensino, por parte dos pesquisadores.

\section{RESULTADOS E ANÁLISES}

Os participantes foram questionados quanto à frequência de acesso ao SIGAA. Quanto a esse dado, parte significativa, quase $59 \%$, respondeu que acessaram 4 ou mais vezes. Já os dados de estatística do próprio sistema indicam que os participantes acessaram mais vezes; 1 participante respondeu que não acessou 0 AVEA em nenhum momento durante a investigação.

De forma geral os participantes aprovaram a Turma Virtual do SIGAA, quando perguntados se prefeririam outro ambiente virtual em detrimento ao atual eles responderam, majoritariamente, que não $(94,1 \%)$. Apenas 1 participantes preferiria utilizar o Moodle. Não foram coletados dados sobre o conhecimento 
para uma provável indicação de que esse Sistema, no tocante à Turma Virtual, poderia ser utilizado de forma mais efetiva e regular nas ações de sala de aula.

O SIGAA foi desenvolvido, originalmente, para ser um sistema de gestão acadêmica, mas na atualidade desempenha além do papel de sistema acadêmico o de AVEA. A Turma Virtual do SIGAA não possui alguns recursos típicos de AVEA, como wiki (texto colaborativo) e glossário, quando questionado, aos participantes, quais recursos o SIGAA deveria possuir, os resultados foram que para $59 \%$ texto colaborativo, $35 \%$ responderam o glossário e $6 \%$ os dois recursos.

Quando os participantes foram perguntados se o SIGAA atendia as necessidades do IFAL, os resultados foram que para $59 \%$ atende ou atende totalmente e $41 \%$ que atende parcialmente. Os participantes apontaram o SIGAA como responsivo e capaz de satisfazer as necessidades de cursos presenciais.

Já em relação à organização dos recursos que resulta na facilidade de acesso, é para $88 \%$ boa à excelente e $12 \%$ regular. Como os participantes estavam há 4 anos na instituição no momento que responderam, pode haver uma falha cognitiva, ou viés, da confirmação, que pode ocorrer quando o participante acredita que o sistema possui boa organização porque ele já conhece a localização de todas as funções (KAHNEMAN, 2012, p. 106). Porém, mesmo a existência de uma possível falha cognitiva não invalida o resultado, visto que nenhum participante apontou a organização como ruim, o que indica que houve uma certa facilidade no uso e não houve lembranças de dificuldade de acesso.

Tanto um sistema acadêmico quanto um AVEA possuem funcionalidades diferentes disponíveis para cada tipo/perfil de conta de usuário. Essa diferenciação é uma necessidade própria da função que cada um desempenha.

Quando o acesso decorre no perfil "aluno", o sujeito acessa sua conta no SIGAA e são exibidas seis opções, cada uma com um grupo de funcionalidades: Turmas, Alunos, Materiais, Atividades, Estatística e Ajuda. Cada um desses grupos possui várias funcionalidades semelhantes, exceto a opção Ajuda que possui um link que leva o usuário ao manual do discente do SIGAA.

Os resultados mostram que os participantes acessaram vários recursos típicos de AVEA e outros tipicamente de sistema acadêmico, como Calendário De Avaliações, Frequência e Notas, no intuito de verificar a parcialidade e os resultados de seus estudos.

As respostas de algumas questões confirmam um comportamento previsto dos participantes, como a avaliação dos recursos da Turma Virtual como importante ou não. Ela mostrou que entre os recursos preferidos dos participantes estão o calendário de avaliações e a possibilidade de acompanhar sua frequência.

As respostas revelam que menos da metade dos participantes marcaram o compartilhamento de arquivos como umas das funções mais úteis, bem como as três formas de tarefas (Online, Offline e Envio de Arquivo).

Quando pedido para que os participantes avaliassem o grau de importância de cada recurso segundo uma lista com cinco opções, começando em sem importância até muito importante. Para facilitar a compreensão dos resultados foi atribuído pesos com valores numéricos para cada nível de ambas as questões variando de 0 a 4, sendo o 0 para sem importância e o 4 para muito importante. 
As notas atribuídas por cada participante para cada recurso foram somadas e, assim, tem-se um valor numérico indicando a nota geral dada para cada um deles, facilitando a compreensão de quais foram mais bem avaliados. A nota geral de cada recurso pode variar de zero, caso todos dessem nota 0 , até sessenta e oito (68), caso todos os 17 participantes atribuíssem nota 4. Esse raciocínio foi usado nas duas questões mencionadas ( 2 e 15 ) e os resultados da questão 2 , estão dispostos na Figura 5.

Figura 5 - Importância de cada recurso

\section{IMPORTÂNCIA DO RECURSOS}

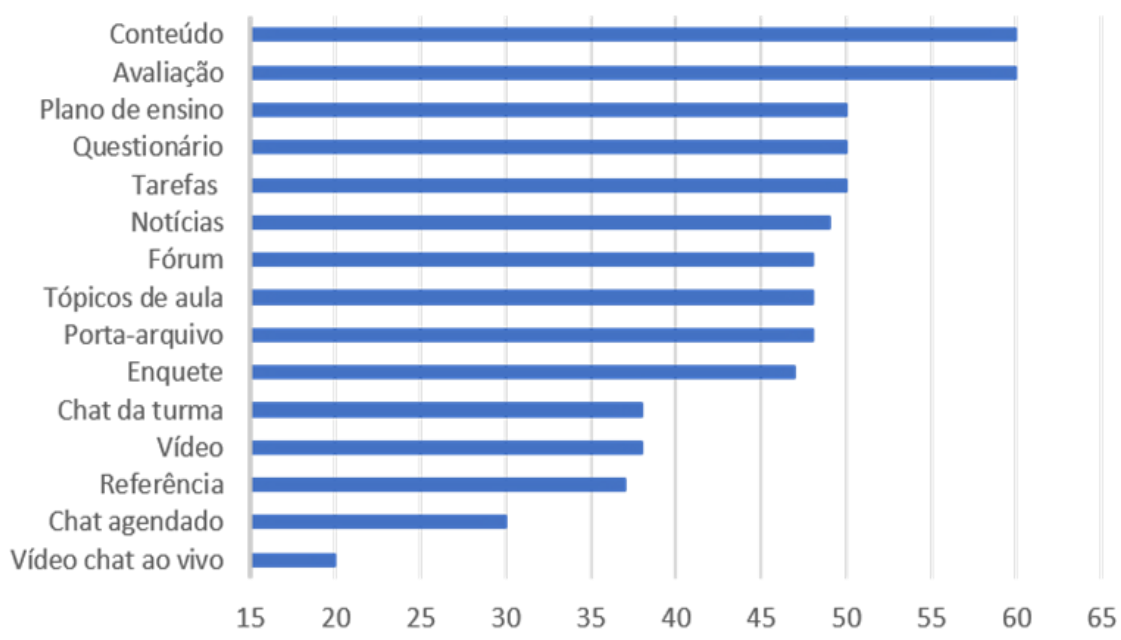

Fonte: Autores (2018).

Como o grau de importância está sendo medido em uma escala de zero (0) a sessenta e oito (68) seu valor médio é trinta e quatro (34), o gráfico da Figura 5 mostra que quase todos os recursos tiveram nota acima do valor médio, exceto o vídeo chat ao vivo e o chat agendado. A média aritmética de todas as notas foi de, aproximadamente, 45, o que indica que, de forma geral, as funcionalidades do SIGAA são entendidas pelos participantes como importantes ou muito importantes.

Quando perguntado sobre a qualidade dos recursos, as respostas foram sensivelmente mais positivas, a média das notas aumentou para 47,5 , ficando o Tópico de Aula como o único recurso que ficou abaixo do valor médio.

Os resultados do questionário apontam ainda que $65 \%$ dos participantes frequentemente acessam o sistema a partir de smartphones. Durante a intervenção houve alguns relatos de falhas no sistema, e nestes, os acessos foram, em sua maioria, nesses aparelhos. Falhas na exibição das notas, ao tentar responder o questionário, anexar documentos em tarefas e até no login. As mesmas observações foram apresentadas no questionário. Além disso, também indicaram a instabilidade, dificuldade de acesso, problema na conexão e "quedas" recorrentes.

Isso pode indicar que o sistema precisa passar por revisões no que tange ao seu uso em aparelhos móveis, adequando suas funcionalidades às características desses equipamentos o que seria um significativo ganho para o SIGAA em alinhar- 
se às tecnologias móveis, seguindo uma tendência que, embora para esse estudo, não tenhamos procurado registro, mostra-se em ascensão de uso.

\section{CONSIDERAÇÕES FINAIS}

O estudo aponta que o AVEA do SIGAA foi aceito pelos participantes da pesquisa. A maioria deles acredita que a Turma Virtual está sendo subutilizada e preferem o SIGAA em detrimento de outros ambientes virtuais. Estes resultados indicam uma satisfação com sistema existente e um anseio de utilizar mais o ambiente. Mesmo em um cenário onde a maior parte dos sujeitos utilizou o SIGAA via um dispositivo móvel, sem possuir a melhor experiência de uso possível a aprovação do sistema foi muito boa. Sendo assim, a criação de um aplicativo para acesso da Turma Virtual por um dispositivo móvel possui grande potencial de melhoria na experiência.

Deste modo, não é possível estruturar a aba principal do SIGAA como é organizado no Moodle, por exemplo. Como o docente deve criar um tópico de aula para cada dia de aula o ambiente fica com um número muito grande de tópicos, o que dificulta o acesso a alguns arquivos ou tarefas, pois o discente teria que procurar em um tópico específico. Uma possível solução é ocultar os tópicos que não tenham atividades, arquivos nem outra informação anexa.

Deste modo, não é possível estruturar a aba principal do SIGAA como é organizado no Moodle, por exemplo. Como o docente deve criar um tópico de aula para cada dia de aula que tenha o número de tópicos pode aumentar de volume, consoante às aulas ministradas; o que pode dificultar o acesso a algum arquivo ou tarefa, visto que se deve procurar em um tópico específico. Uma possível solução é ocultar os tópicos que não tenham atividades, arquivos nem outra informação anexa.

O acesso ao SIGAA pode ser feito de diversas plataformas, a principal é usando um navegador em computador de mesa ou um notebook. Outra forma de acesso é via smartphone ou tablet ambas com acesso via navegador, haja visto que o Sistema possui um aplicativo utilizado exclusivamente na UFRN.

Quando o acesso é realizado por dispositivos móveis o sistema apresenta dois modos: Modo Mobile e o Modo Clássico. O primeiro é muito resumido, vários recursos são omitidos, como tarefas, questionários, notas e outros, basicamente o usuário docente acessa apenas os tópicos de aula e a frequência. Já o segundo modo é igual ao tipo de acesso por computador de mesa, esse mostra todos os recursos. Mesmo nesse segundo caso, a experiência de uso fica limitada, visto que a navegação é comprometida devido ao tamanho da tela (principalmente em smartphones).

Devido a flexibilidade de uso, o SIGAA mostra-se vantajoso para docentes e discentes. Os docentes do IFAL já precisam registrar nele as funções acadêmicas, assim, seu uso como AVEA fica facilitado visto que já possui conhecimento sobre a disposição das funcionalidades. A maioria dos participantes aprovam a organização e a disposição dos recursos no ambiente.

Quando o docente utiliza o sistema de forma consistente facilita que as informações importantes cheguem aos seus discentes. Deste modo, os discentes acessam rapidamente aos conteúdos didáticos, as datas de avaliação, as atividades 
e demais materiais didáticos digitais disponíveis, o que facilita o atendimento ao aluno.

O uso dos recursos de ambiente virtual do SIGAA mostra-se efetivo como uma forma de integrar as ações desenvolvidas pelos discentes para além da sala de aula com as ações presenciais. Esse uso rompe as barreiras da distância facilitando o processo de ensino-aprendizagem e agilizando a avaliação do discente. Por esse motivo, indica-se que o uso desse instrumento deve ser permanente na disciplina.

Pelo exposto, esta pesquisa indica como ações de melhoria no ambiente a criação de um aplicativo específico para dispositivos móveis, pois, além de potencializar a experiência do usuário também melhoraria a percepção de instabilidade visto que o aplicativo não necessitaria do site funcionando permanentemente, mas apenas quando fosse sincronizar as informações, bem como uma organização mais atrativa dos tópicos de aulas o que facilitaria, sobremaneira, a navegação pelos espaços disponíveis no SIGAA. 


\title{
THE USAGE OF SIGAA: A CASE STUDY ABOUT THE TEACHING LEARNING PROCESS IN THE CURRICULAR COMPONENT ELECTRIC MACHINES IN THE ELECTROELECTRIC TECHNICAL COURSE
}

\begin{abstract}
This study investigates the usage of the pedagogical potentialities of SIGAA as an integral part of educational actions in technical courses in face-to-face teaching. This investigation has been developed using action research methodology and considered the research subject perceptions and their reflections about the usage of resources of the virtual learning environment. For data collection, a questionnaire, and the SIGAA Statistics resources, the researchers' records and findings and a semi-structured questionnaire applied to the participants were used. The results show that the participants of this study perceive the contribution of this System in the teaching learning process and suppose that it is underused, due to the lack of compatibility of smartphones. With some exceptions about access via mobile and punctual instabilities, the SIGAA facilitates and expands access to materials and didactic content worked, contributes with the interaction between teacher and student and assists in their exams, showing itself as an ally in face-to-face teaching.
\end{abstract}

KEYWORDS: Virtual learning environment. Face-to-face teaching. Action research. SIGAA. Virtual classroom. 


\section{REFERÊNCIAS}

ALVES, J. R. M. A história da EAD no Brasil. In: Educação a distância: o estado da arte. São Paulo: Pearson Education do Brasil, 2009. v. 1. 9-13.

FILHO, I. B.; AQUINO, G.; ROSA, J. G. S. SIGAA Mobile - O caso de sucesso da ferramenta de gestão acadêmica na era da computação móvel. Brazilian Symposium on Computers in Education (Simpósio Brasileiro de Informática na Educação - SBIE), p. 92, 2013.

CARVALHO, R. R. N. O uso do SIGAA como ferramenta de aprendizagem no curso de letras inglês da UFPB. 2018. Monografia (Graduação) - Departamento de Letras Estrangeiras Modernas, Universidade Federal da Paraíba. João Pessoa, 2018.

COSTA, P. S.; MENDONÇA, L. S. O uso da plataforma Moodle como apoio ao ensino presencial. Revista Eletrônica da Divisão de Formação Docente, v. 2, n. 1, p. 146-193, 2014.

DELGADO, L. M. M.; HAGUENAUER, C. J. Uso da plataforma Moodle no apoio ao ensino presencial: um estudo de caso. Educaonline, v. 4, n. 1, p. 11-26, 2010.

DELORENZO. Máquinas elétricas rotativas DL 10280: laboratório Openlab. v. 1, 2009.

GERBASI, N. T. O. D.; SILVA, A. K. A. Compartilhamento de informações e socialização do conhecimento tácito por meio de ambientes virtuais: Uma análise na comunidade do SIGAA/UFPB. Pesq. Bras. em Ci. da Inf. e Bib., v. 12, n. 1, p. 166-176, 2017.

GUÉRIOS, E.; SAUSEN, S. Ambiente virtual de aprendizagem e educação presencial: uma integração possível na formação de professores. Praxis Educativa, v. 7, n. 2, p. 559-584, 4 dez. 2012.

KAHNEMAN, D. Rápido e devagar: duas formas de pensar. 1. ed. Rio de Janeiro: Objetiva, 2012.

NETO, A. F. R.; LIMA, G. A. F. Turma Virtual do SIGAA como ferramenta de apoio ao ensino. Natal, 2009. Disponível em: <https://storage.googleapis.com/googlecode-archive-downloads/v2/code.google.com/s2dg/19695.pdf $>$. Acesso em: 5 ago. 2018. 
NUNES, I. B. A história da EAD no mundo. In: Educação a Distância: estado da arte. São Paulo: Pearson Education do Brasil, 2009. v. 1. p. 461.

OECD/PISA. PISA 2015 Results in Focus. Paris: OECD, 2018.

OLIVEIRA, D. T.; CORTIMIGLIA, M. N. Ambientes virtuais de aprendizagem no ensino superior presencial: análise de um caso bem-sucedido de difusão da tecnologia. Revista Ibero-americana de Educação, v. 69, n. 3, p. 9-26, 2015.

PEREIRA, A. T. C.; SCHMITT, V.; DIAS, M. R. A. C. Ambientes Virtuais de Aprendizagem. p. 1-22, 2007.

RIBEIRO, E. A. A perspectiva da entrevista na investigação qualitativa. Evidências, v. 4, n. 4, p. 129-148, 2008.

RODRIGUES, L. C. et al. Uso de ambiente virtual de aprendizagem como auxílio ao ensino presencial de linguagem de programação. VI Workshop de Pós-

Graduação e Pesquisa do Centro Paula Souza, 2011.

SANTOS, W. R.; TOCZEK, J.; GIMENES, S. S. A utilização dos recursos EAD como apoio ao ensino presencial na educação básica. Revista Brasileira de Ensino de Ciência e Tecnologia, v. 7, n. 1, p. 107-118, 2014.

SILVA, C. G.; FIGUEIREDO, V. F. Ambiente virtual de aprendizagem: comunicação, interação e afetividade na EAD. Revista Aprendizagem em EAD, v. 1, p. 1-16, 2012.

SINFO. Sistemas Institucionais Integrados de Gestão - SIG. Disponível em: <https://docs.info.ufrn.br/doku.php?id=suporte>. Acesso em: 15 set. 2017a.

SINFO. SIGAA - Sistema Integrado de Gestão de Atividade Acadêmica. Disponível em: <https://docs.info.ufrn.br/doku.php?id=suporte:sigaa:visao geral >. Acesso em: 13 set. $2017 \mathrm{~b}$.

SINFO. Módulo Ambiente Virtual de Aprendizado. Disponível em:

$<$ https://docs.info.ufrn.br/doku.php?id=suporte:manuais:sigaa:turma virtual:list a >. Acesso em: 9 ago. 2018.

THIOLLENT, M. Metodologia da pesquisa-ação. 18. ed. São Paulo: Cortez, 2011. 
TORI, R. Cursos híbridos ou blended learning. In: Educação a distância: o estado da arte. Pearson Education do Brasil, 2009. v. 1p. 121-128.

TRIPP, D. Pesquisa-ação: uma introdução metodológica. Educação e Pesquisa, v. 31, n. 3, p. 443-466, dez. 2005.

YUNOKI, B. T. Utilização do Moodle como ambiente de apoio ao ensino presencial: estudo de caso do curso de Biblioteconomia da Universidade de Brasília. Monografia (Graduação) - Departamento de Ciência da Informação e Documentação, Universidade de Brasília. Brasília, 2009.

Recebido: 30 out. 2019

Aprovado: 15 jul. 2020.

DOI: 10.3895/rbect.v13n3.11021

Como citar: LOPES-SILVA, P. W.; GOMES, E. F. O uso do SIGAA: um estudo de caso sobre o processo de ensino-aprendizagem no componente curricular máquinas elétricas no curso técnico em eletroeletrônica. Revista Brasileira de Ensino de Ciência e Tecnologia, Ponta Grossa, v.13, n. 3, p. 367-385, set./dez. 2020. Disponível em: <https://periodicos.utfpr.edu.br/rbect/article/view/11021>. Acesso em: XXX.

Correspondência: Paulo Wagner Lopes-Silva - paulo.wagner@ifal.edu.br

Direito autoral: Este artigo está licenciado sob os termos da Licença Creative Commons-Atribuição 4.0 Internacional. 